\title{
Gene expression profiles of novel caprine placental prolactin-related proteins similar to bovine placental prolactin-related proteins
}

\author{
Koichi Ushizawa ${ }^{1}$, Toru Takahashi*1, Misa Hosoe ${ }^{1}$, Keiichiro Kizaki², \\ Yasuyuki Abe $^{3}$, Hiroshi Sasada ${ }^{3}$, Eimei Sato ${ }^{3}$ and Kazuyoshi Hashizume ${ }^{2}$
}

Address: ${ }^{1}$ Reproductive Biology Research Unit, Division of Animal Sciences, National Institute of Agrobiological Sciences, 2 Ikenodai, Tsukuba, Ibaraki 305-8602, Japan, ²Department of Veterinary Medicine, Faculty of Agriculture, Iwate University, 3-18-8 Ueda, Morioka, Iwate 020-8550, Japan and ${ }^{3}$ Laboratory of Animal Reproduction, Graduate School of Agricultural Sciences, Tohoku University, 1-1 Tsutsumidori-amamiyamachi, Aoba-ku, Sendai, Miyagi 981-8555, Japan

Email: Koichi Ushizawa - ushizawa@affrc.go.jp; Toru Takahashi* - tatoru@affrc.go.jp; Misa Hosoe - hosoe@affrc.go.jp; Keiichiro Kizaki - kizaki@iwate-u.ac.jp; Yasuyuki Abe - abe-y@bios.tohoku.ac.jp; Hiroshi Sasada - hsasada@bios.tohoku.ac.jp; Eimei Sato - eimei@bios.tohoku.ac.jp; Kazuyoshi Hashizume - kazuha@iwate-u.ac.jp

* Corresponding author

Published: 15 March 2007

BMC Developmental Biology 2007, 7:16 doi:10.1186/147/-213X-7-16
Received: 26 September 2006

Accepted: 15 March 2007

This article is available from: http://www.biomedcentral.com/147/-2/3X/7/16

(c) 2007 Ushizawa et al; licensee BioMed Central Ltd.

This is an Open Access article distributed under the terms of the Creative Commons Attribution License (http://creativecommons.org/licenses/by/2.0), which permits unrestricted use, distribution, and reproduction in any medium, provided the original work is properly cited.

\begin{abstract}
Background: This study reports the identification of a full-length cDNA sequence for two novel caprine prolactin-related proteins (cPRPI and CPRP6), and their localization and quantitative expression in the placenta. Caprine PRPs are compared with known bovine PRPs. We examined their evolution and role in the ruminant placenta.
\end{abstract}

Results: Full-length cPRPI and cPRP6 cDNA were cloned with a 717- and 720- nucleotide openreading frame corresponding to proteins of 238 and 239 amino acids. The cPRPI predicted amino acid sequence shares a $72 \%$ homology with bovine PRPI (bPRPI). The cPRP6 predicted amino acid sequence shares a 74\% homology with bovine PRP6 (bPRP6). The two cPRPs as well as bPRPs were detected only in the placentome by RT-PCR. Analysis by in situ hybridization revealed the presence of both cPRPs mRNA in the trophoblast binucleate cells. These mRNA were quantified by real-time RT-PCR analysis of the placentome at 30,50, 90 and I 40 days of pregnancy. Both new CPRP genes were able to translate a mature protein in a mammalian cell-expression system. Western blotting established the molecular sizes of $33 \mathrm{kDa}$ for cPRPI with FLAG-tag and $45 \mathrm{kDa}$ for CPRP6 with FLAG-tag. The sequence properties and localized expression of CPRPI and CPRP6 were similar to those of bovine. However, their expression profiles differed from those in bovine placenta. Although this study demonstrated possible roles of PRPs in caprine placenta, PRPs may regulate binucleate-cell functions like those in bovine, but their crucial roles are still unclear.

Conclusion: We have identified the novel PRPs in caprine placenta. Localization and quantitative expression of caprine PRPs were compared with bovine PRPs. The data indicate that PRP genes in caprine placenta have coordination functions for gestation, as they do in bovine. This is the first study of PRPs function in caprine placenta. 


\section{Background}

In ruminant placenta, various kinds of functional molecules such as steroid hormones, peptides, and prostanoids are expressed. These molecules contribute to a successful pregnancy and to the establishment of placenta. It is known that placental lactogen (PL) $[1,2]$, pregnancy-associated glycoproteins (PAGs) [3-5], and interferon- $\tau$ (IFNT) [6-8] specifically appear in both caprine (goat) and bovine trophoblast. Prolactin-related protein (PRP) has been known as a placental-specific molecule that specifically expresses in trophoblastic binucleate cells in cattle. PRP is a gene of a non-classical member of the prolactin (PRL)/growth hormone (GH) family [9,10]. At least thirteen members are known to occur in cattle, and their nucleotide sequences are significantly analogous to PRL and PL in bovine species [11-13]. In rodents, diversity of the PRL family has been reported as well as the fact that they take on regulatory roles in pregnancy $[14,15]$. The placental PRL families in mouse and rat may play similar roles because of the evolutionary role of these genes in establishing pregnancy [15]. In the ruminants, bovines have some PRPs $[12,13]$; however there is no report on this in caprine species. We investigated the PRPs mRNA in caprine placenta. This paper introduces two novel types of cPRP genes that emerged from the cloning of a complete sequence of full-length cDNA and its expression. We named these sequences caprine prolactin-related protein1 (CPRP1) and caprine prolactin-related protein- 6 (cPRP6), based on their similarity to bovine PRPs.

\section{Results}

Sequences of CPRPI and CPRP6 CDNA and deduced amino acids

Sequences of 933 and 957 nucleotides were isolated from caprine placentome and cloned as candidates of cPRP1 and $C P R P 6$. The predicted protein sequence regions (CDSs) were composed of 717 nucleotides in $C P R P 1$ and 720 nucleotides in cPRPG. The amino acid sequences deduced from full-length $c P R P 1$ and $C P R P 6$ cDNA are 238 and 239 amino acids (aa). The $c P R P 1$ and $c P R P 6$ sequences were submitted to the DNA Data Bank of Japan (DDBJ), and the DDBJ/GenBank/EMBL accession numbers are AB231295 and AB231296. A homology search can determine intermolecular similarity. It is also possible to learn the stage of the molecular evolution with the speed from the branching and distance in a phylogenetic analysis. We analyzed the evolutionary interrelationships using predicted amino acids (aa) sequences between the cPRPs and bPRPs (Fig. 1). The cPRP6 aa sequence was $\sim 74 \%$ homologous to bPRP6 (Fig. 2B), so it was named cPRP6. In contrast, the sequence homology of cPRP1 is closer to a cluster of bPRP1, bPRP2, bPRP4, bPRP9 and bPRP12 (called the "bPRP1 cluster"). This aa sequence was $72 \%$ homologous to bPRP1, 61\% homologous to bPRP2, 72\% homologous to bPRP4, 76\% homologous to
bPRP9, and 71\% homologous to bPRP12 (Fig. 2A). The predicted CPRP1 sequence was closest to bPRP9, but it was located outside of the bPRP1 cluster according to the phylogenetic tree analysis. CPRP1 changed in the an earlier stage which was earlier than the bPRP1 cluster when, the amino acid evolution was decided from the phylogenetic analysis. Therefore, this novel caprine sequence was named cPRP1. The predicted 3D structures of cPRP1, bPRP1, cPRP6 and bPRP6 mature regions are illustrated in Fig. 3. The structural differences in the $N$-glycosylation site, the disulfide bond (-S-S-), and each atomic configuration were confirmed.

\section{Localized and quantitative mRNA expression}

RT-PCR analysis confirmed $c P R P 1$ and $c P R P 6$ expression in placenta such as $b P R P 1$ and $b P R P 6$ in bovine. No amplification was found in other caprine tissue, i.e. heart, liver, lung, kidney, spleen or endometrium (Fig. 4).

The mRNA localization was determined by in situ hybridization in the caprine or bovine placenta on day 50 (caprine) or 60 (bovine) of gestation (Fig. 5). Anti-sense RNA probes specifically detected mRNA transcripts in the placenta. All PRPs signals appeared in binucleate cells in the cotyledonary villous (Figs. 5A, B, D, E, G and 5H). No significant signals were detected with sense probes in any genes (Figs. 5C, F and 5I).

Quantitative real-time RT-PCR analysis showed that the cPRP1 and $C P R P 6$ expression intensities increased from Day 30 to Day 50 and then remained constant to Day 90 and thereafter decreased until Day 140 in placentome (the cotyledonary and caruncular parts were not able to separate (PTM); see Fig. 6). In the caprine intercotyledon (the area between the cotyledonary villous (ICOT)), the $c P R P 1$ expression intensity held steady from Day 30 to Day 90 and thereafter decreased until Day 140, although the intensity was low compared to that in PTM. The cPRP6 expression intensity increased from Day 30 to Day 50 and thereafter decreased until Day 140 in PTM, but rather low expressions were found in ICOT. The profile of $c P R P 1$ was weaker than $b P R P 1$ through the pregnancy. Especially $b P R P 1$ intensively expressed in placentomal and interplacentomal tissues.

\section{Translation of CPRP I and cPRP6}

Cloning sequences of $C P R P 1$ and $C P R P 6$ were effectively translated in an HEK293 cell system, like bovine PRPs (Fig. 7). Two different sizes of protein were translated of $\sim 30$ and $33 \mathrm{kDa}$ with a FLAG-tag in cPRP1. Those translated-protein sizes were close to those in bPRP1 (Fig. 7A). However, translated cPRP6 was larger than bPRP6, at 45 $\mathrm{kDa}$ and $29 \mathrm{kDa}$. There was a difference of $>15 \mathrm{kDa}$ between the bovine and caprine values. From the sequence analysis, there were no differences between 


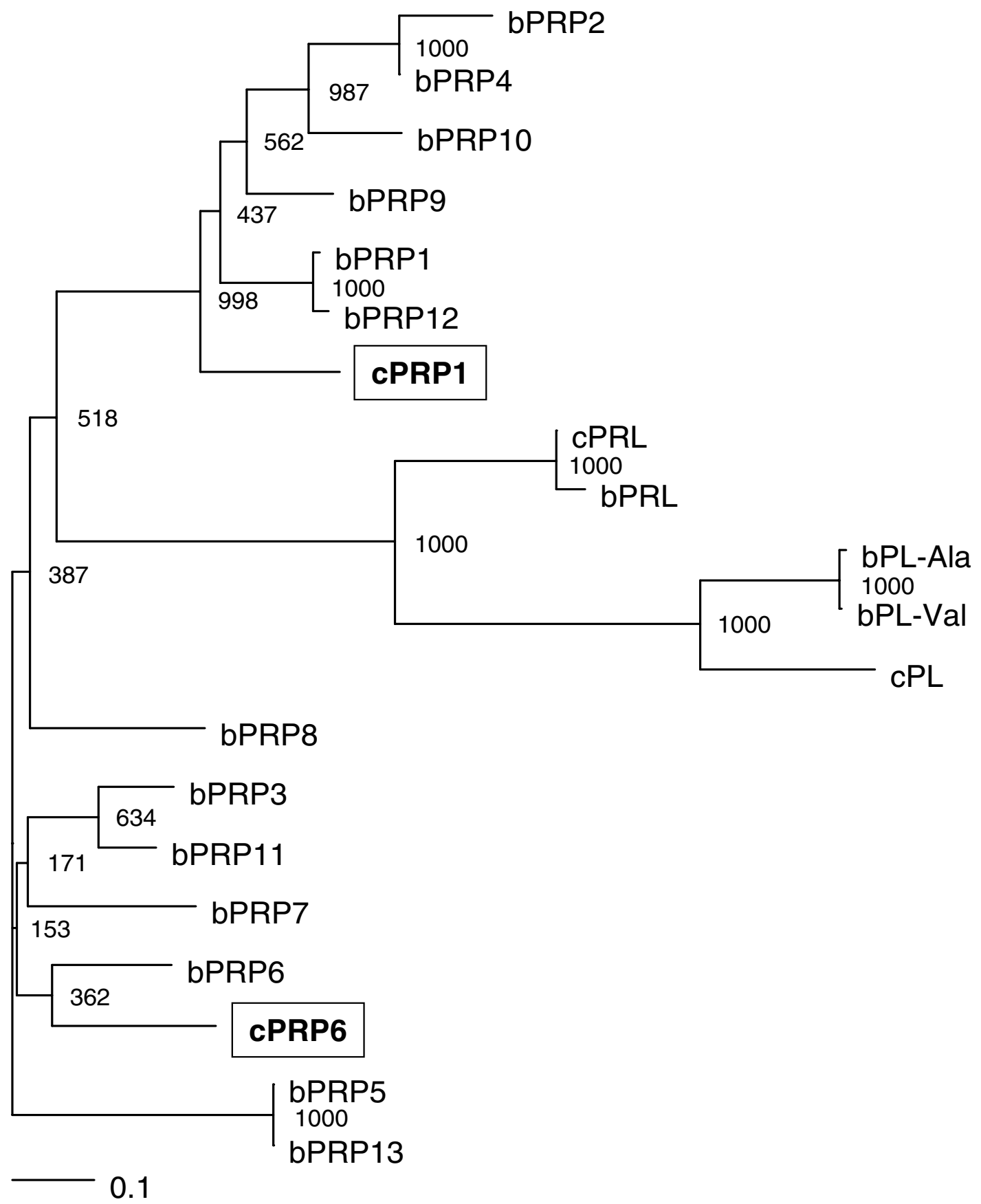

Figure I

Phylogenetic tree of prolactin and placental-prolactin family of caprine and bovine. The tree was constructed using TreeView following the alignment of protein sequences given by the Clustal W I.83 algorithm. The numbers at the base of each branch division represent bootstrap values after 1000 repeats. The scale bar represents 0.1 amino acid replacements per amino acid site. For GenBank/DDBJ accession numbers, refer to Materials and Methods. 


\section{A}

CPRP1

bPRP1

bPRP2

bPRP4

bPRP9

bPRP12

CPRP1

bPRP1

bPRP2

bPRP4

bPRP9

bPRP12

CPRP1

bPRP1

bPRP2

bPRP4

bPRP9

bPRP12

CPRP1

bPRP1

bPRP2

bPRP4

bPRP9

bPRP12

B

CPRP6

bPRP 6

CPRP6

bPRP 6

CPRP6

bPRP 6

CPRP6

bPRP6

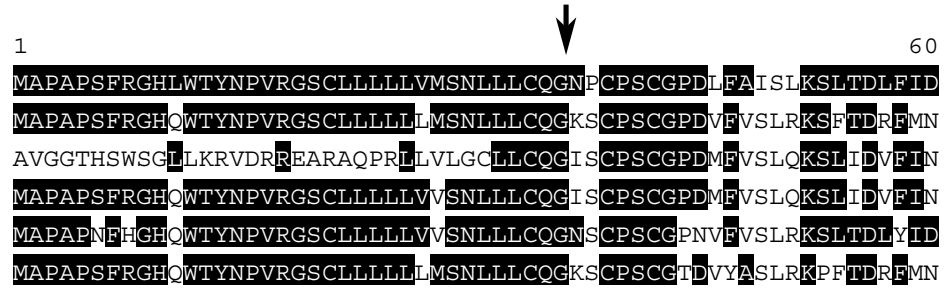

61

ATLLSHEFHNVSA VMFKEFNEKYAQGKLYHINATNSCHTNSFHSPEDRYKAHQLNNEDLS AASLSHDGYNLSTI MFNEFD EKYAQGKLYYINVTKSCHTNSFHA PEERDIVQ $T$ TNIEDLS AASLSHDFHNLSTIMFNEFDEKYAQGKLYYINATKSCHTNSFHTPEERDKAQOMNNEDLS AASLSHDFHNLSTIMFNEFDEKYAOGKLYYINATKSCHTNSFHT DEERDKARQQMNNEDLS AA WLSHEFHNLSA MESEFKEKYAQGKLYHINATNSCHTNSFHA PEERDKA HOMNNEDLS AASLSHDFYNLSTIMFNEFDEKYAOGKLYYINVTKSCHTNSFHADEERDIVQQTNIEDLS

121

180

KWTLVLLYSWNNPLYHLVMELP SMRELSETFLSSARKMETMSDKLQAFIESHFRKI IAAV KWTLVLLYSWNNPLHHLVTELQHMKELSNA FLSSATRFENMSEKLQAFIERQESSKIIVPV KWTLVLLYSWNNPLYYLLLELRNMKKLSEAVISSAME IENMSEKLQAF IESOFRKI IVPV KWTLVLLYSWNNPLYYLLLELRNMKNLSEAVISSAMEI ENMSEKLQAF IESQFRKI IVPV KWTLVLLYSWNNPLYHLVPRLRNMKNLSEAVVSSAMEI IENMSDKLQAFIESOFRKVIVSV KWTLVLLYSWNNPLHHLVTELOHMNKLLSNAELSSATRFENMS EKLQAF IEROESKI IVPV

181

238

LQTMHDADSSWSRLPSLTSSEEDRRHSELYNLFHCLRRDAGKVDMYIKILACRTRGTC LNTMI $Q$ ARSSWTGLPSLMSSA EDRRHSEF YNLFYCLRRDSRKVDMY IKILTCRTHKTC LKMIHEVSNTWSRFSSMTT SDEDRS ISEYYNLFYCLRRDSRKVDMYIKILTCRTRKTC LKMIHEVSDTWSRFSSMTF SDEDRS I SEYYNLFYCLRRDSRKVDMY IKILTCRTRKTC LKTIHEARSSWSGLPSLTSSDEDRRL SEFYNLFHCLHRDS GKVDTYIKILTCRIRKKC LNTMI A ARSSWTGLPSLMSSD EDRRHSEF YNLFYCLRRD SRKVDMYIKILTCRTHKTC

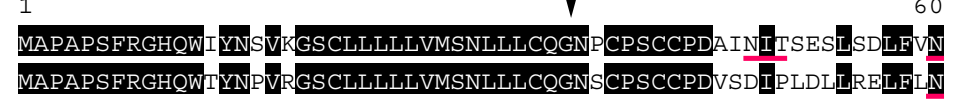

$61 \quad 120$

ATMLSYRMYNHSRIMFNEFD KYAKGKLYYFSATNSCHTNFLKTPEE I KEAEKMNNEDLS ATLLSOS I LKHSRIMLNEFDEKYAOGKLYYLTATKSCHTNSLHTTEDMDKAEKIDNEDLS

Figure 2

Comparison of amino-acid sequences of (A) cPRP I with bPRP I cluster and (B) cPRP6 with bPRP6. Residues identical to cPRPI (A) or cPRP6 (B) are shown in black boxes. Amino acid sequences were aligned with assistance from Clustal W I.83 on the DDBJ web site. The arrow indicates the putative primary cleavage site of the signal peptide of cPRPI or cPRP6. The potential $N$-glycosylation site is underlined with a red line. 

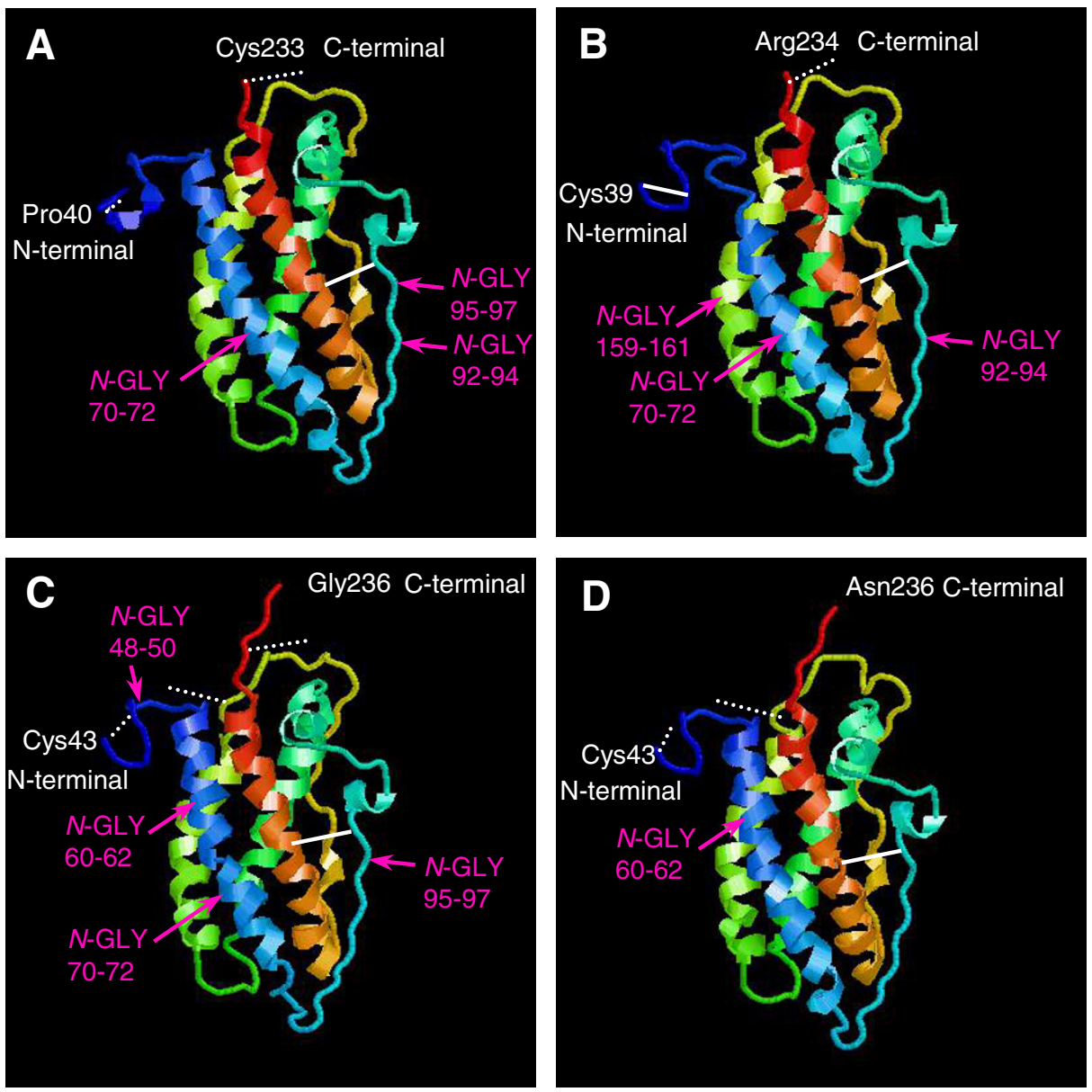

\section{Figure 3}

Predicted 3D structure of (A) cPRPI, (B) bPRPI, (C) cPRP6 and (D) bPRP6 mature protein. The 3D structures were predicted by the FAMS software. The cPRPI structure was able to construct from Pro 40 to the Cys 233 amino acid region. The bPRPI structure was able to construct from Pro39 to the Arg234 amino acid region. The cPRP6 structure was able to construct from Cys43 to the Gly236 amino acid region. The bPRP6 structure was able to construct from Cys 43 to the Asn236 amino acid region. White solid lines indicate disulfide bonds. White dotted lines indicate predicted disulfide bonds. $N$ GLY refers to a potential $N$-glycosylation site.

them in predicted size (Fig. 7B). These PRPs were migrated to $26 \mathrm{kDa}$ by $\mathrm{N}$-deglycosylation treatment (Fig. 7).

\section{Discussion}

The diversity of the PRL gene family has been shown in mouse, rat and cattle; however, there exists only limited functional information except for PRL, PL and some rodents PLPs [11,14-18]. In particular, ruminants commonly have various genes of this family, but there is no information regarding goats, even though anatomical evidence shows a similarity to the placenta in ruminants. In cattle, thirteen varieties of PRP paralogs have been reported. In the present study, we identified novel PRPs in caprine and compared the properties of goat and cattle.
Novel PRP1 and PRPG genes were detected and cloned from caprine placenta and their deduced amino acid sequences were determined to have some specific properties. Phylogenetic analysis suggests that cPRP1 separated from bovine PRP1 cluster in an early evolutionary stage (Fig. 1). In contrast, cPRP6 and bPRP6 molecules were phylogenetically adjacent (Fig. 1). This indicates that a primitive PRP6 molecule existed before it evolved into caprine and bovine.

The N-terminal regions of the bPRP1 and bPRP6 proteins were rich in hydrophobic amino acid residues, which is characteristic of the signal peptide $[19,20]$. The signal peptide sequence of CPRP1 and CPRP6, composed of 36 amino acids, is well conserved in bPRP1 and bPRP6. This 


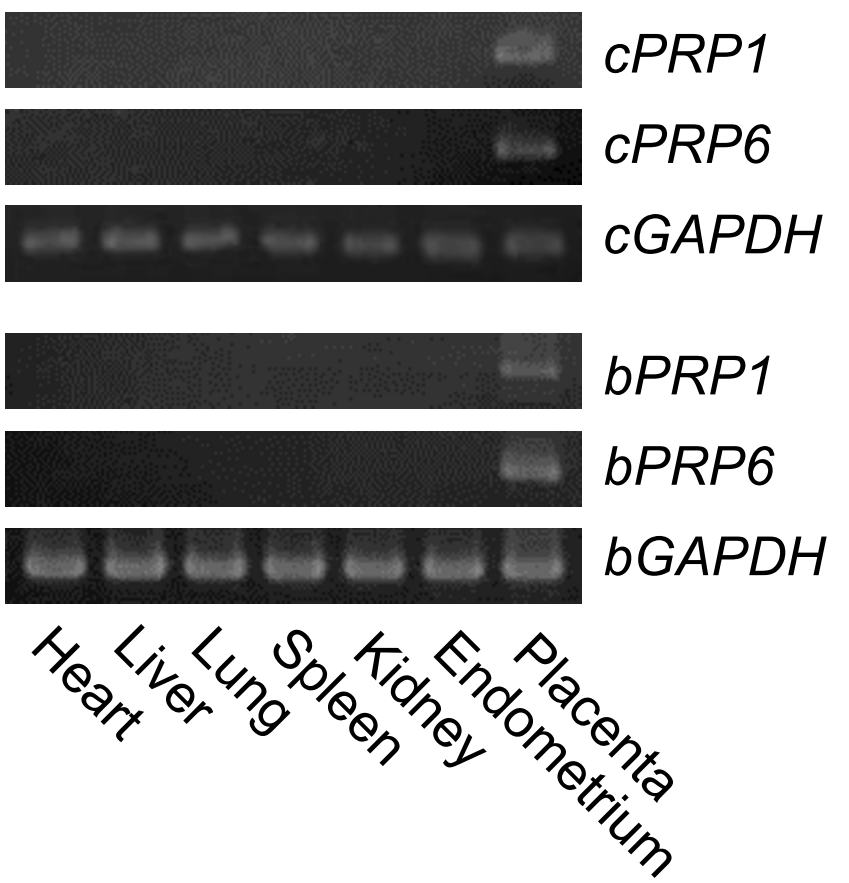

Figure 4

Expression of cPRPI, cPRP6, bPRPI and bPRP6 mRNA in caprine and bovine tissues. Heart, liver, lung, spleen, kidney, and endometrium were used by RT-PCR. Caprine placentomal tissue at Day 50 of gestation or bovine cotyledonary tissue at Day 60 of gestation were used as placental samples. Caprine or bovine GAPDH expression in each tissue is presented as standard data.

information suggests that the signal cleavage site (between the Glu-36 and Arg-37) of cPRPs is the same as that of bPRPs (Fig. 2).

The bPRP1 mature protein is predicted to have three S-S bonds with six cysteines (Cys) at 39, 42, 97, 215, 232, and 238 (Figs. 2A, 3A, and 3B) $[12,19]$. The numbers and positions for these in the predicted CPRP1 exactly coincide with those of bPRP1. The 3D structure of CPRP 6 was also similar to that of the mature bPRP6 protein (Fig. 3). bPRP6 is predicted to have three S-S bonds with six cysteines (Cys) in the sequence. However, cPRP6 mature protein is predicted to have eight Cys, with six Cys in aa positions at 39,42,43, 97, 174, and 215 corresponding with those in bPRP6 and an extra two in positions 232 and 239 (Figs. 2B, 3C, and 3D) [12,20]. However, these two last Cys were present in most other bPRPs, including bPRP1 (Figs. 2 and 3). Therefore PRP6 may have a highly homologous sequence in caprine and bovine, with a slight difference in 3D structure.

cPRP1 has two consensus sequences for potential N-glycosylation sites (Asn-X-Ser/Thr) at positions 70-72 and
92-94 (Figs. 2A and 3A), and an atypical N-glycosylation site, Asn-X-Cys was found at position 95-97. Typically, bPRP1 had three potential N-glycosylation sites at positions 70-72, 92-94 and 159-161 (Figs. 2A and 3B) [19]. So, the potential $\mathrm{N}$-glycosylation sites are different in bovine and caprine, but the number of sites is the same, so they may translate a similar molecular size. This expectation was supported by the result of HEK 293 cell translation at $33 \mathrm{kDa}$ (Fig. 7A).

cPRP6 had three consensus sequences for $N$-glycosylation at positions 48 to 50,60 to 62, and 70 to 72 (Figs. 2B and $3 \mathrm{C}$ ) with the atypical $N$-glycosylation site (Asn-X-Cys) at position 95-97 as in CPRP1. However, bovine PRP6 had only one consensus sequence for a typical potential $N$-glycosylation, at position 60-62. (Figs. 2B and 3D) $[12,20]$. This is a unique $N$-glycosylation position in caprine and bovine, which is not present in the CPRP1 and bPRP1 cluster genes (bPRP1, bPRP2, bPRP4, bPRP9 and bPRP12) (Fig. 1). N-glycosylation positions of 92-94 were confirmed in all PRP aa sequences except for caprine and bovine PRP6. In comparing the $N$-glycosylation sites in CPRP6 and bPRP6, the caprine may have four sites and bPRP, one site. Western blot analysis of an HEK293 cell system showed that cPRP6 migrated to $45 \mathrm{kDa}$ and bPRP 6 migrated to $29 \mathrm{kDa}$ (Fig. 7B). Both $N$-degrycosylated proteins were migrated to $\sim 26 \mathrm{kDa}$ (Fig. $7 \mathrm{~B}$ ). The difference in the size of the proteins is related to the sugar-chain status.

Primary mRNA expression of $C P R P 1$ and $C P R P 6$ was observed in trophoblast binucleate cells (Fig. 5), and HEK293 cells translated these mRNA to each protein individually. Both $c P R P s^{\prime}$ mRNA were expressed in the extraembryonic membrane after the implantation period (Fig. 6). In the bovine, $b P R P 1$ and $b P R P 6$ expression were found in the trophoblast binucleate cells (Fig. 5) and their expressions were kept from the implantation to late pregnancy in the placentomal villi (Fig. 6). The trophoblast binucleate cells are also primary expression cells for the bPRPs [21-25] and may have specific roles for the implantation and placentation of the fetomaternal interface [2628]. The two caprine PRPs may also be related to implantation or placentation, like the bovine PRPs, since the localization and stage of expression of both caprine PRP1 and PRPG were similar to those of bovine PRPs. The functional roles may not coincide between CPRP1 and bPRP1 (or CPRP6 and bPRP6), since the PRP1 and PRP6 expression profiles are different from those for bovine (Fig. 6). The bovine placental weight increases from the early to late stage of gestation [29]. In contrast, small ruminant placental weight increases to the middle stage of gestation (Days 70 to 80) and decreases to the late stage of gestation [30]. The change of the placental weight correlates with the placentation. The bPRPs expression appears to relate to 

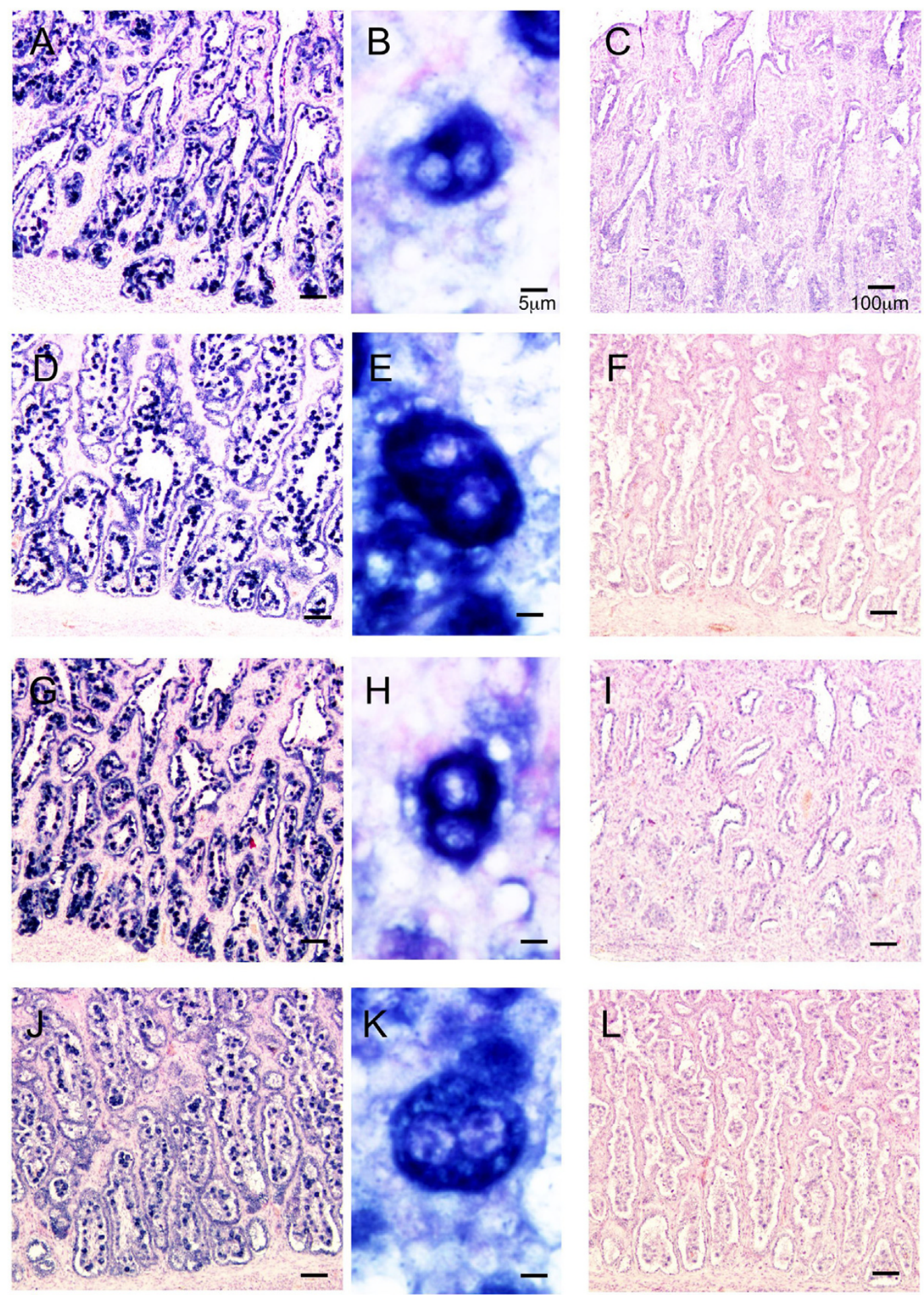

Figure 5

Localization of $c P R P I, c P R P 6, b P R P I$ and $b P R P 6$ in the caprine and bovine placentome on Day 50 and $\mathbf{6 0}$ of gestation. (A, B, C) cPRPI , (D, E, F) cPRP6, (G, H, I) bPRPI, and (J, K, L) bPRP6 mRNA were detected by in situ hybridization. (A, B, $D, E, G, H, J, K)$ DIG-labeled anti-sense cRNA probes were used. (C, F, I, L) DIG-labeled sense cRNA probes were used. Seven micrometer sections of caprine and bovine placentome were hybridized with each probe. Scale bar $=100 \mu \mathrm{m}$ on $(A, C, D, F$, $\mathrm{G}, \mathrm{I}, \mathrm{J}, \mathrm{L})$ and $5 \mu \mathrm{m}$ on $(\mathrm{B}, \mathrm{E}, \mathrm{H}, \mathrm{K})$. 
A

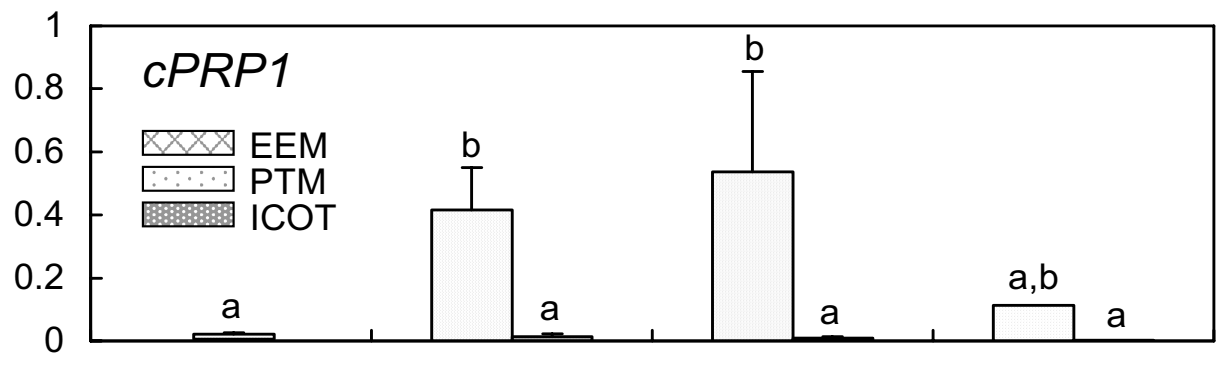

Day 30

Day 50

Day 90

Day 140

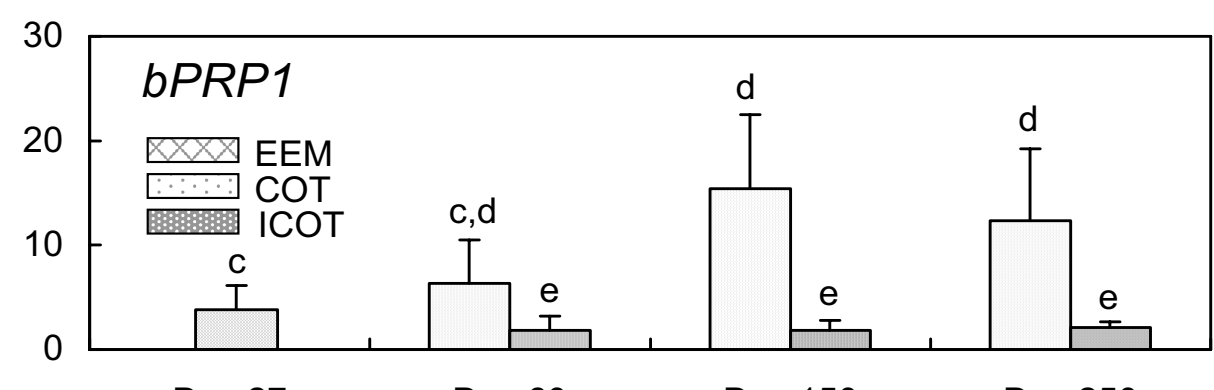

Day 27

Day 60

Day 150

Day 250

B

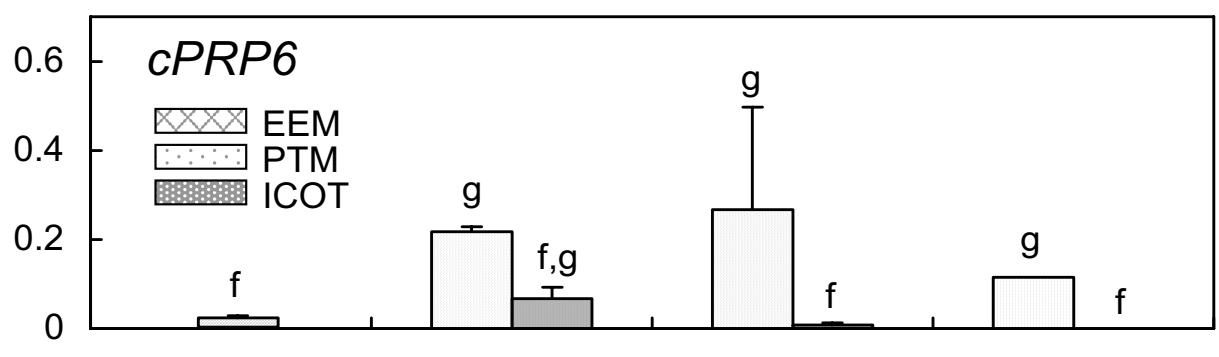

Day 30

Day 50

Day 90

Day 140

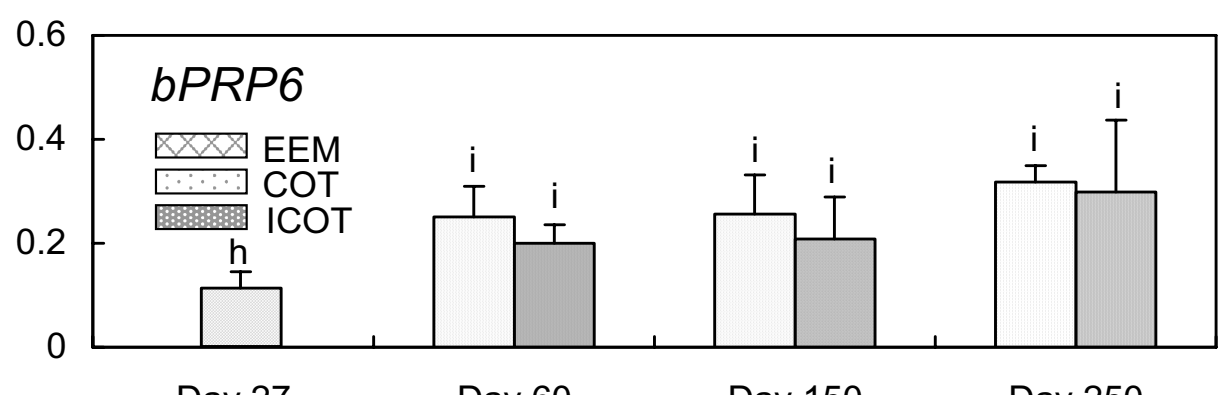

Day 27

Day 60

Day 150

Day 250

Figure 6

Quantitative real-time RT-PCR analysis of (A) CPRPI and bPRPI, (B) CPRP6 and bPRP6 mRNA in caprine or bovine placenta. The total RNA of caprine was extracted from cotyledons containing extra-embryonic membrane (EEM), placentome (PTM), and intercotyledonary fetal membrane (ICOT) on Day 30, Day 50, Day 90 and Day I 40 of gestation. The total RNA of bovine was extracted from cotyledons containing extra-embryonic membrane (EEM), cotyledonary placenta (COT), and intercotyledonary fetal membrane (ICOT) on Day 27, Day 60, Day 150, and Day 250 of gestation. The expression of these mRNAs was normalized to the expression of GAPDH measured in the corresponding RNA preparation. Values are mean $\pm S D$. Values with different letters are significantly different $(P<0.05)$. 

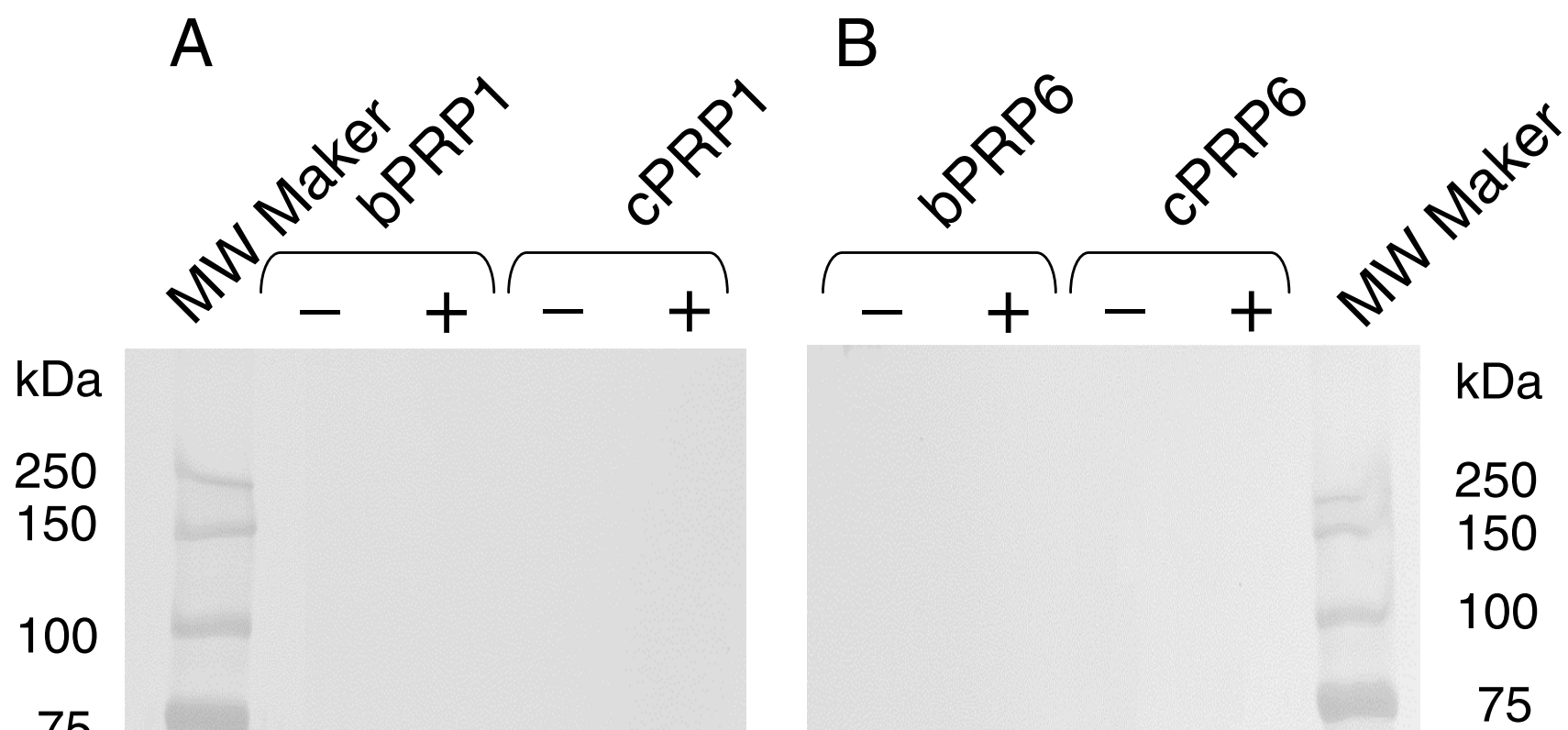

75

75

50

37

25

20

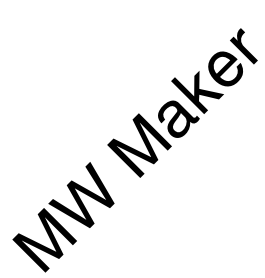

kDa

250

150

100

50

37

25

20

\section{Figure 7}

Western blot analysis of recombinant FLAG-tag fusion (A) cPRPI and bPRPI, (B) cPRP6 and bPRP6 proteins. Conditioned media from HEK 293 cells transiently transfected with each gene were collected, and the purified proteins (I ng) were loaded in separate lanes. The proteins were separated by SDS PAGE and specific proteins were detected by Western blot analysis using an anti-FLAG antibody. (-): Non N-degrycosylation treatment; (+): N-degrycosylation treatment; MW Marker: molecular weight marker. 
the placentation in bovine ICOT. In contrast, the placentation decrease in the goat after the mid-pregnancy may be related to the low $C P R P S$ expression in the ICOT.

It is important to confirm the caprine PRPs in order to understand the mechanism of implantation and placentation in small ruminant. Until now, the placental hormone in a small ruminant has been considered without PRP [31]. We suggest that PRP is also related to the placentalspecific endocrine activity in a small ruminant.

\section{Conclusion}

In conclusion, we have found two PRPs in caprine placenta. These PRP sequences had a high homology with the sequence of bovine PRPs. These PRPs were expressed in trophoblast binucleate cells as are bovine PRPs. They expressed from after the implantation period to late in gestation. These genes could independently produce mature recombinant proteins in a mammalian cellexpression system. We were able to specify the PRP genes, which was alike between the ruminants. Finally, we suggest that the caprine may have many more PRPs, recalling that thirteen PRPs or sixteen PLPs have been discovered in bovine or rodents.

\section{Methods}

\section{Animals and tissues}

Caprine placental tissues intended for cDNA cloning and mRNA expression were collected from Japanese Saanen goats. Extra-embryonic tissues and placenta were collected on days 26 to 30,50 to 52,86 to 92 , and 135 to 139 after artificial insemination or natural mating (designated as day 1 of pregnancy). The tissues were obtained into two portions; the PTM and ICOT. It was difficult to divide the cotyledon (COT) and ICOT on days 26 to 30 , and thus the COT contained very few villi. Tissues from three different goats on day 30 and one cow on day 26 of gestation $(n=$ 4) were used as Day 30 extra-embryonic membrane (Day 30 EEM). Placentomal tissues were collected on days 50 (two samples), and 52 (two samples) (in total, $\mathrm{n}=4$ ) and designated as Day 50 PTM and ICOT. Sample materials from days 86 (one samples) and 92 (three sample) (in total, $\mathrm{n}=4$ ) and days 135 (one sample) and 139 (one samples) (in total, $\mathrm{n}=2$ ) were marked as Day 90 PTM, ICOT, Day 140 PTM, and ICOT. The collected tissues were stored at $-80^{\circ} \mathrm{C}$ until RNA extraction. Some of the placentomes from day 50 were fixed in $3.7 \%$ formaldehyde PBS (pH 7.4), embedded in paraffin wax and stored at $4{ }^{\circ} \mathrm{C}$ for in situ hybridization. Details of bovine placental-tissue collection have been provided in previous reports $[21,22]$. All procedures for these animal experiments were carried out in accordance with guidelines and ethical standards approved by the Animal Ethics Committee of the Laboratory Animals for Biomedical Research of the Graduate School of Agricultural Science, Tohoku University and
National Institute of Agrobiological Sciences for the use of animals.

\section{Cloning of full-length cPRPI and CPRP6 CDNA}

The new full-length $c P R P 1$ and $c P R P G$ CDNA was isolated from caprine cotyledonary tissue by the 3'-rapid amplification of cDNA ends (RACE) method. In brief, a complete RNA was isolated from a caprine placentome from day 50 of gestation using ISOGEN (Nippon Gene, Toyama, Japan). We performed 3'-RACE using a 3'-full RACE core set (Takara, Kyoto, Japan) with a $c P R P 1$-specific forward primer (5'-CCACAGTCAACAGGAGTCCTC-3') and a cPRP6-specific forward primer (5'-CCAACAGAGAGTCCTCACCCTGCGA-3'). Both $C P R P$ primers were designed from a bovine $P R P$ sequence. The 3'-RACE products were sequenced using an ABI Prism 370 automatic sequencer (Applied Biosystems, Foster City, CA, USA) after cloning in a pGEM-T Easy Vector (Promega, Madison, WI, USA).

\section{Phylogenetic analysis}

The deduced CPRP1 and CPRP6 protein sequences were aligned with bPRPs using the multiple-alignment software Clustal W 1.83 found on the DDBJ web site. Clustal $\mathrm{W}$ was also employed to calculate trees using the Neighbor-Joining (NJ) method [32]. TreeView was used to display the phylogenetic tree $[33,34]$. The values represent bootstrap scores for 1,000 trials, indicating the credibility of each branch. Except for the cPRP1 and cPRP6 sequences, the bPRPs and bPL protein sequences were obtained from GenBank. Their GenBank accession numbers are: bPRP1 (022944), bPRP2 (․27239), bPRP3

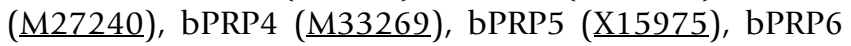
(AB245482), bPRP7 (ㅅ187564), bPRP8 (AB196438), bPRP9 (AB204881), bPRP10 (AB255602), bPRP11 (BK005438), bPRP12 (BK005439), bPRP13 (BK005440), bPL-Ala (022840), bPL-Val (ㅆ33268), bPRL (NM 173953) and CPRL ( $\underline{\text { X76049)}}$ ). The cPL sequence was obtained from Sakal et al. [1].

\section{Three-dimensional structure prediction by FAMS}

We predicted the three-dimensional (3D) structure of CPRP1, bPRP1, cPRP6 and bPRP6 using the FAMS (Fully Automated Homology Modeling System) [35,36]. FAMS is a software program that predicts $3 \mathrm{D}$ models for target proteins based on the structure of known proteins of high homology. For CPRP1, bPRP1, cPRP6 and bPRP6, the 3D structure was constructed based on the human prolactin (hPRL) 3D structure (Protein Data Bank ID: 1N9D). The FAMS program requires only an amino-acid sequence as input, and constructs 3D model structures automatically. Visualization of the 3D structure was performed using RasMol 2.7.3 software [37,38]. 


\section{RT-PCR}

The tissue distribution of $c P R P 1, c P R P G, b P R P 1$, and bPRPG expression was studied using RT-PCR. Caprine or bovine GAPDH was used as a positive control for the PCR. Details of the RT-PCR method have been described in previous reports $[21,22]$. The total RNA in a total reaction mixture was used for reverse transcription and template cDNA synthesis using oligo(dT) primer and Superscript III reverse transcriptase (Invitrogen, Carlsbad, CA, USA) at $50^{\circ} \mathrm{C}$ for $50 \mathrm{~min}$. Each PCR contained a cDNA template, primers, deoxynucleotide triphosphate mixture (dNTP), $\mathrm{MgCl}_{2}, 10 \times$ PCR buffer II, autoclaved milliQ water, and AmpliTaq gold DNA polymerase (Applied Biosystems). Amplification conditions included denaturation at $95^{\circ} \mathrm{C}$ for $30 \mathrm{sec}$ and extension at $72^{\circ} \mathrm{C}$ for $1 \mathrm{~min}$. Twenty six cycles were performed for all samples. The annealing temperature was set at $60^{\circ} \mathrm{C}$ for $30 \mathrm{sec}$. A single denaturation step at $95^{\circ} \mathrm{C}$ for $10 \mathrm{~min}$ before the first PCR cycle and a final extension step at $72^{\circ} \mathrm{C}$ for $10 \mathrm{~min}$ after the last PCR cycle were also performed. The PCR products were analyzed by agarose-gel electrophoresis and visualized by ethidium bromide staining. The primers encoding for the cPRP1, cPRPG, bPRP1, and bPRPG sequences were designed using our obtained sequences (caprine) and GenBank accession No. J02944 and AB245482 (bovine). The designated primers are listed in Table 1. All the primers were commercially synthesized (Tsukuba Oligo Service, Tsukuba, Japan).

\section{In situ hybridization}

The full-length cDNA of $c P R P 1, c P R P 6, b P R P 1$, and $b P R P 6$ was used as a template for hybridization-probe synthesis. Complementary digoxigenin (DIG)-labeled antisense and sense RNA probes were prepared as described in previous studies [21,22]. The Day 50 caprine and Day 60 bovine placentomes were sectioned into $7 \mu \mathrm{m}$-thick sections for hybridization. In situ hybridization was performed using the automated Ventana HX System Discovery with a RiboMapKit and BlueMapKit (Ventana, Tucson, AZ, USA)
$[21,22]$. Briefly, caprine and bovine sections were hybridized with DIG-labeled probes in a RiboHybe (Ventana) hybridization solution at $60^{\circ} \mathrm{C}(c P R P 1), 63^{\circ} \mathrm{C}(c P R P 6)$, $65^{\circ} \mathrm{C}(b P R P 1)$, or $67^{\circ} \mathrm{C}$ (bPRP 6$)$, for $6 \mathrm{~h}$. The sections were washed three times in RiboWash (Ventana) (at $60^{\circ} \mathrm{C}, 63^{\circ} \mathrm{C}, 65^{\circ} \mathrm{C}$, or $67^{\circ} \mathrm{C}$, for $6 \mathrm{~min}$ ) after hybridization and were fixed in RiboFix (Ventana) (at $37^{\circ} \mathrm{C}$, for 10 min). The hybridization signals were detected with monoclonal-anti-digoxin biotin conjugate (Sigma, Saint Louis, MI, USA) and the biotin localized with the alkaline phosphatase system. The hybridized glasses were observed after preparation with a Leica DMRE HC microscope (Leica microsystems, Wetzlar, Germany) with a Fujix digital camera HC2500 (Fujifilm, Tokyo, Japan).

\section{Real-time RT-PCR}

Gene expression of $c P R P 1, c P R P 6, b P R P 1$, and $b P R P 6$ was confirmed quantitatively at each stage of gestation by realtime RT-PCR analysis using the SYBR Green assay. Fifty ng of the total RNA was reverse transcribed into cDNA for 30 min at $48^{\circ} \mathrm{C}$ by MultiScribe ${ }^{\mathrm{TM}}$ reverse transcriptase with a random primer, dNTP mixture, $\mathrm{MgCl}_{2}$ and RNase inhibitor. In the SYBR Green assay, primer pairs were designed using the Primer Express 1.0 software program (Applied Biosystems). The primers for each gene are listed in Table 2. Thermal-cycling conditions included initial-sample incubation at $50^{\circ} \mathrm{C}$ for $2 \mathrm{~min}$ and at $95^{\circ} \mathrm{C}$ for $10 \mathrm{~min}$, followed by 40 cycles at $95^{\circ} \mathrm{C}$ for $15 \mathrm{sec}$ and at $60^{\circ} \mathrm{C}$ for 1 min. The cycle-threshold values $\left(\mathrm{C}_{\mathrm{T}}\right)$ indicate the quantity of the target gene in each sample and were determined in real time using an ABI Prism 7700 sequence detector (Applied Biosystems). The relative difference in the initial amount of each mRNA species (or cDNA) was determined by comparing the $\mathrm{C}_{\mathrm{T}}$ values. The standard curves for each gene were generated by serial dilution of plasmid containing $c P R P 1, c P R P 6, c G A P D H, b P R P 1, b P R P 6$, or $b G A P D H$ cDNA to quantify the mRNA concentrations. The ratios of $c P R P 1 / c G A P G H, c P R P 6 / c G A P G H, b P R P 1 / b G A P G H$ and $b P R P 6 / b G A P G H$ mRNA were calculated to adjust for any

Table I: Oligonucleotide primers used for RT-PCR analysis

\begin{tabular}{|c|c|c|c|}
\hline Gene & Primer & Sequence & Position \\
\hline CPRPI & Forward & 5' TGTCCCACGAGTTCCATAACGT 3' & $237-258$ \\
\hline$(A B 231295)$ & Reverse & 5' GCACGCCAGGATCTTGATGTA 3' & $742-722$ \\
\hline CPRP6 & Forward & 5' TCACCTCAGAATCCCTTTCAGA 3' & $38-59$ \\
\hline$(A B 23 \mid 296)$ & Reverse & 5' CATGCCATGAGCTTGGTGTAA 3' & $587-567$ \\
\hline cGAPDH & Forward & 5' GACCCCTTCATTGACCTTCAC 3' & $|-2|$ \\
\hline$(\mathrm{AJ} 43 \mathrm{I} 207)$ & Reverse & 5' TCATAAGTCCCTCCACGATGC 3' & $424-404$ \\
\hline bPRPI & Forward & 5' CTAATCTGCTCCTGTGCCAAGG 3' & $173-194$ \\
\hline$(\mathrm{J02944)}$ & Reverse & 5' ATGACGCCTATCTTCAGCGCT 3' & $705-685$ \\
\hline bPRP6 & Forward & 5' TGTCCTGACGTGTCTGACATCC 3' & $19-40$ \\
\hline$(\mathrm{AB} 245482)$ & Reverse & 5' GCAGGCAGTGGAACAGGCTATA 3' & $54 I-520$ \\
\hline$b G A P D H$ & Forward & 5' CCTTCATTGACCTTCACTACATGGTCTA 3' & $71-98$ \\
\hline (U85042) & Reverse & 5' GCTGTAGCCAAATTCATTGTCGTACCA 3' & $927-901$ \\
\hline
\end{tabular}


Table 2: Oligonucleotide primers used for Real-time RT-PCR analysis

\begin{tabular}{|c|c|c|c|}
\hline Gene & Primer & Sequence & Position \\
\hline CPRPI & Forward & 5' CAAATCTGCTCCTGTGCCAA 3' & $|32-15|$ \\
\hline$(A B 23 \mid 295)$ & Reverse & 5' AAGGAGATGGCGAACAAGTCA 3' & $198-178$ \\
\hline bPRPI & Forward & 5' TCGTGTTGCTGTACTCCTGGAA 3' & $458-479$ \\
\hline (J02944) & Reverse & 5' GGAAGGCGTTTGACAGTTCTTT 3' & $54 I-520$ \\
\hline CPRP6 & Forward & 5' GATATTTACACCAAGCTCATGGCA 3' & $562-585$ \\
\hline$(A B 231296)$ & Reverse & 5' GGATGGCATGGATGTGGATT 3' & $631-612$ \\
\hline bPRP6 & Forward & 5' GGAGAATAATATTTACTGGTCGGGAC 3' & $447-472$ \\
\hline (AB245482) & Reverse & 5' AAAATGCAGAATGACGCACATCT 3' & $520-498$ \\
\hline CGAPDH & Forward & 5' GCCATCACCATCTTCCAGGA 3' & $115-134$ \\
\hline$(\mathrm{A} / 43 \mathrm{I} 207)$ & Reverse & 5' CCACGTACTCAGCACCAGCA 3' & $184-165$ \\
\hline bGAPDH & Forward & 5' AAGGCCATCACCATCTTCCA 3' & $178-197$ \\
\hline (U85042) & Reverse & 5' CCACTACATACTCAGCACCAGCAT 3' & $253-230$ \\
\hline
\end{tabular}

variations in the RT-PCR reaction. All values are presented as mean \pm SD. Statistical analysis was performed using one-way ANOVA followed by the Tukey-Kramer multiplecomparison test. Differences were considered significant at $P<0.05$.

\section{Production and purification of recombinant proteins}

The $C P R P 1, c P R P 6, b P R P 1$, and $b P R P 6$ sequences encoding the mature-protein region, which combined the FLAG and $6 \times$ His epitope tag sequences, were inserted into the pFLAG-CMV-3 vector (Sigma). The constructed plasmid was transfected into HEK 293 cells using FuGENE 6 (Roche Diagnostics, Basel, Switzerland) for transient transfection. Stably transfected HEK 293 cells were adapted to the suspension culture in a spinner flask using 293 SFM II medium (Invitrogen, Gibco) and cultured in an atmosphere of $5 \% \mathrm{CO}_{2}$ in air at $37^{\circ} \mathrm{C}$ for 3 days. The medium was separated by centrifugation.

Recombinant FLAG-tag and $6 \times$ His-tag fusion proteins were purified using the $6 \times$ His-tag portion. Approximately 1 liter of conditioned medium was processed at a time. A medium to which $1 \mathrm{ml} \mathrm{Ni}$ Sepharose 6 Fast Flow (Amersham Bioscience, Buckinghamshire, UK) was added was mixed and equilibrated with a $20 \mathrm{mM}$ sodium-phosphate buffer, $\mathrm{pH}$ 8.0, containing $300 \mathrm{mM} \mathrm{NaCl}$ and 20 $\mathrm{mM}$ imidazole. Only the $6 \times$ His-tag proteins bind to the Ni Sepharose 6 Fast Flow carrier. The medium with carrier was chromatographed on a PD-10 column (Amersham Bioscience). The fractions with carrier were washed in the $20 \mathrm{mM}$ imidazole. The fractions were eluted by $250 \mathrm{mM}$ imidazole. We also examined the cutting of the carbohydrate chain modified for the proteins using $\mathrm{N}$-Glycosidase F Deglycosylation kit (Roche).

\section{Western blot analysis}

One ng of purified proteins was loaded on each lane, separated by SDS-PAGE, and electrophoretically transferred onto a polyvinylidene-difluoride membrane [39]. West- ern blotting was performed using the method of Towbin et al. [40]. Briefly, the membrane was blocked in $10 \%$ skimmed milk overnight and incubated with mouse antiFLAG M2 (Sigma) for $1 \mathrm{~h}$ at room temperature, followed by incubation with anti-mouse IgG conjugated with alkaline phosphatase (Sigma) (diluted 1:3000) for $1 \mathrm{~h}$ at room temperature. Immunopositive bands were stained using NBT (Bio-Rad, Hercules, CA, USA) and BCIP (BioRad).

\section{Authors' contributions}

KU participated in the design of the study, and carried out most of the experiments. TT participated and coordination in the design of the study, and performed the recombinant protein productions and Western blotting. KU, TT, $\mathrm{MH}, \mathrm{KK}$ and $\mathrm{KH}$ collected the tissue samples of goats and cattle. YA, HS and ES carried out all animal care and tissues collection. KH participated and coordination in the design of the study, and helped to draft the manuscript. All authors read and approved the final manuscript.

\section{Acknowledgements}

This research was supported by a grant from the Research Project for Utilizing Advanced Technologies (05-1770) from the Ministry of Agriculture, Forestry, and Fisheries of Japan; grants (Kiban-kenkyu C 17580284; Kibankenkyu B 17380 I72) from the Ministry of Education, Culture, Sport, Science, and Technology of Japan; and a grant from the Animal Remodeling Project (05-20I) at the National Institute of Agrobiological Sciences.

\section{References}

I. Sakal E, Bignon C, Chapnik-Cohen N, Daniel N, Paly J, Belair L, Djiane J, Gertler A: Cloning, preparation and characterization of biologically active recombinant caprine placental lactogen. J Endocrinol 1998, 159:509-518.

2. Schuler LA, Shimomura K, Kessler MA, Zieler CG, Bremel RD: Bovine placental lactogen: molecular cloning and protein structure. Biochemistry 1988, 27:8443-8448.

3. Garbayo JM, Green JA, Manikkam M, Beckers JF, Kiesling DO, Ealy $A D$, Roberts RM: Caprine pregnancy-associated glycoproteins (PAG): their cloning, expression, and evolutionary relationship to other PAG. Mol Reprod Dev 2000, 57:3 II-322.

4. Garbayo JM, Remy B, Alabart JL, Folch J, Wattiez R, Falmagne P, Beckers JF: Isolation and partial characterization of a pregnancy- 
associated glycoprotein family from the goat placenta. Biol Reprod 1998, 58:109-115.

5. Green JA, Xie S, Quan X, Bao B, Gan X, Mathialagan N, Beckers JF, Roberts RM: Pregnancy-associated bovine and ovine glycoproteins exhibit spatially and temporally distinct expression patterns during pregnancy. Biol Reprod 2000, 62:1624-|63|.

6. Baumbach GA, Duby RT, Godkin JD: N-glycosylated and unglycosylated forms of caprine trophoblast protein-I are secreted by preimplantation goat conceptuses. Biochem Biophys Res Commun 1990, I72:16-21.

7. Ealy AD, Wagner SK, Sheils AE, Whitley NC, Kiesling DO, Johnson SE, Barbato GF: Identification of interferon-tau isoforms expressed by the peri-implantation goat (Capra hircus) conceptus. Domest Anim Endocrinol 2004, 7:39-49.

8. Farin CE, Imakawa K, Hansen TR, McDonnell Jן Murphy CN, Farin PW, Roberts RM: Expression of trophoblastic interferon genes in sheep and cattle. Biol Reprod 1990, 43:210-218.

9. Kessler MA, Milosavljevic M, Zieler CG, Schuler LA: A subfamily of bovine prolactin-related transcripts distinct from placental lactogen in the fetal placenta. Biochemistry I989, 28:5I54-5I6I.

10. Yamakawa M, Tanaka M, Koyama M, Kagesato Y, Watahiki M, Yamamoto M, Nakashima K: Expression of new members of the prolactin growth hormone gene family in bovine placenta. Isolation and characterization of two prolactin-like cDNA clones. J Biol Chem 1990, 265:8915-8920.

II. Takahashi T: Biology of the PRL family in bovine placenta. I. Bovine placental lactogen: expression, structure and proposed roles. Anim SciJ 2006, 77:10-17.

12. Ushizawa K, Hashizume K: Biology of the PRL family in bovine placenta. II. Bovine prolactin-related proteins: their expression, structure and proposed roles. Anim Sci J 2006, 77: 18-27.

13. Larson JH, Kumar CG, Everts RE, Green CA, Everts-van der Wind A, Band MR, Lewin HA: Discovery of eight novel divergent homologs expressed in cattle placenta. Physiol Genomics 2006, 25:405-4I3

14. Soares MJ: The prolactin and growth hormone families: pregnancy-specific hormones/cytokines at the maternal-fetal interface. Reprod Biol Endocrinol 2004, 2:5 I.

15. Soares MJ, Alam SMK, Konno T, Ho-chen JK, Ain R: The prolactin family and pregnancy-dependent adaptations. Anim Sci J 2006 77:1-9.

16. Al-Gubory KH, Camous S, Germain G, Bolifraud P, Nicole A, Ceballos-Picot I: Reconsideration of the proposed luteotropic and luteoprotective actions of ovine placental lactogen in sheep: in vivo and in vitro studies. I Endocrinol 2006, 188:559-568.

17. Song G, Bazer FW, Wagner GF, Spencer TE: Stanniocalcin (STC) in the endometrial glands of the ovine uterus: regulation by progesterone and placental hormones. Biol Reprod 2006, 74:913-922.

18. Alam SM, Ain R, Konno T, Ho-Chen JK, Soares MJ: The rat prolactin gene family locus: species-specific gene family expansion. Mamm Genome 2006, 17:858-877.

19. Schuler LA, Hurley WL: Molecular cloning of a prolactin-related mRNA expressed in bovine placenta. Proc Natl Acad Sci USA 1987, 84:5650-5654

20. Tanaka $\mathrm{M}$, Minoura $\mathrm{H}$, Ushiro $\mathrm{H}$, Nakashima $\mathrm{K}$. A novel cDNA clone encoding a prolactin-like protein that lacks the two Cterminal cysteine residues isolated from bovine placenta. Biochim Biophys Acta 199I, 1088:385-389.

21. Ushizawa K, Takahashi T, Hosoe M, Kaneyama K, Hashizume K: Cloning and expression of two new prolactin-related proteins, prolactin-related protein-VIII and -IX, in bovine placenta. Reprod Biol Endocrinol 2005, 3:68.

22. Ushizawa K, Kaneyama K, Takahashi T, Tokunaga T, Tsunoda $Y$, Hashizume K: Cloning and expression of a new member of prolactin-related protein in bovine placenta: bovine prolactin-related protein-VII. Biochem Biophys Res Commun 2005, 326:435-44I.

23. Milosavljevic M, Duello TM, Schuler LA: In situ localization of two prolactin-related messenger ribonucleic acids to binucleate cells of bovine placentomes. Endocrinology 1989, I 25:883-889.

24. Nakano H, Takahashi T, Imai K, Hashizume K: Expression of placental lactogen and cytokeratin in bovine placental binucleate cells in culture. Cell Tissue Res 200I, 303:263-270

25. Patel OV, Yamada O, Kizaki K, Todoroki J, Takahashi T, Imai K, Schuler LA, Hashizume K: Temporospatial expression of placen- tal lactogen and prolactin-related protein-I genes in the bovine placenta and uterus during pregnancy. Mol Reprod Dev 2004, 69: I 46-I52.

26. Yamada O, Todoroki J, Kizaki K, Takahashi T, Imai K, Patel OV, Schuler LA, Hashizume K: Expression of prolactin-related protein $I$ at the fetomaternal interface during the implantation period in cows. Reproduction 2002, 124:427-437.

27. Anthony RV, Liang R, Kayl EP, Pratt SL: The growth hormone/prolactin gene family in ruminant placentae. J Reprod Fertil Suppl 1995, 49:83-95.

28. Ushizawa K, Herath CB, Kaneyama K, Shiojima S, Hirasawa A, Takahashi T, Imai K, Ochiai K, Tokunaga T, Tsunoda Y, Tsujimoto G, Hashizume K: cDNA microarray analysis of bovine embryo gene expression profiles during the pre-implantation period. Reprod Biol Endocrinol 2004, 2:77.

29. Prior PL, Laster DB: Development of the bovine fetus. J Anim Sci 1979, 48: I546-1553.

30. Bell AW, Hay WW Jr, Ehrhardt RA: Placental transport of nutrients and its implications for fetal growth. J Reprod Fertil Suppl 1999, 54:40I-4I0.

31. Gootwine E: Placental hormones and fetal-placental development. Anim Reprod Sci 2004, 82-83:55I-566.

32. Saitou N, Nei M: A neighbor-joining method: a new method for constructing phylogenetic tree. Mol Biol Evol 1987, 44:406-425.

33. Page RDM: TREEVIEW: An application to display phylogenetic trees on personal computers. Comput Appl Biosci 1996 I 2:357-358

34. TreeView [http://taxonomy.zoology.gla.ac.uk/rod/treeview.html]

35. Ogata K, Umeyama H: An automatic homology modeling method consisting of database searches and simulated annealing. I Mol Graphics Mod 2000, 1 8:258-272.

36. Modeling Service for Protein [http://www.pharm.kitasatou.ac.jp/fams/index.html]

37. Bernstein $\mathrm{HJ}$ : Recent changes to RasMol, recombining the variants. Trends Biochem Sci 2000, 25:453-455.

38. RasMol 2.7.3 [http://www.bernstein-plus-sons.com/software/ras $\mathrm{mol} /]$

39. Laemmli UK: Cleavage of structural proteins during the assembly of the head of bacteriophage T4. Nature 1970 227:680-685

40. Towbin H, Staehelin T, Gordon J: Electrophoretic transfer of proteins from polyacrylamide gels to nitrocellulose sheets: procedure and some applications. Proc Natl Acad Sci USA 1979, 76:4350-4354.
Publish with Bio Med Central and every scientist can read your work free of charge

"BioMed Central will be the most significant development for disseminating the results of biomedical research in our lifetime. "

Sir Paul Nurse, Cancer Research UK

Your research papers will be:

- available free of charge to the entire biomedical community

- peer reviewed and published immediately upon acceptance

- cited in PubMed and archived on PubMed Central

- yours - you keep the copyright

Submit your manuscript here:

http://www.biomedcentral.com/info/publishing_adv.asp
BioMedcentral 